\title{
Regional supplier associations as the producers of transnational club goods in Latin American and Caribbean utility markets
}

\author{
Jacqueline Harralla, Sunita Mondal ${ }^{b^{*}}$ \\ a Behavioral Sciences Department, University of Pittsburgh at Greensburg, USA. E-mail:jhorrall@pitt.edu \\ b School of Business, Slippery Rock University, USA. \\ * Corresponding author's email: sunita.mondal@sru.edu
}

H I G H L I G H T S:

1. Study analyzes the functions and impact of collaborations of the utility providers in the Latin American and Caribbean utility markets

2. This information is essential to improving production and supply within regions that could benefit most from cross-border collaboration

3. Study the privately supplied cross-border infrastructure related goods and analyze policy recommendations

4. Results of this study suggest that utilities that formed linkages or cooperation regionally are likely to benefit greatly from such collaborations and that utilities that rely on only national associations derive much smaller benefits.

\section{Article History}

Received: 31-08-2014

Accepted: 11-09-2014

Available online: 13-09-2014

Keywords:

Infrastructure development; Network;

Regional utility operator.

JEL Classification:

054; L94; L97.

The Authors. This is an open access article under the terms of the Creative Commons Attribution License 4.0, which allows use, distribution and reproduction in any medium, provided the original work is properly cited.

\subsection{Introduction}

For over a decade, Latin America and the Caribbean (LAC) have been finding new and unique ways to improve their access to resources and to improve infrastructure within individual nations. In particular, tremendous focus has been concentrated on infrastructure development in the form of telecommunications, water and energy (RTG Report, 2012). The view that utility infrastructure development is essential to encourage and maintain economic development has become a consensus (OFID Quarterly, 2009). As a result, developing countries have focused increasing attention and resources on improving and reforming these sectors as a means of developing sustainable growth within each nation. Much emphasis has been placed on improving the physical aspect of networks, and on providing autonomous, transparent, and effective regulation of these traditionally public utilities once they were privatized. According to Brown et al. (2006), between 1990 and 2006, more than 200 regulatory commissions were created worldwide. Some studies of the contributions of transnational regulatory institutions have been conducted in response to the growth of these networks. Berg and Horrall (2008) provide a detailed description of the role of 
regional regulatory networks and the goods they provide. Globalization has resulted in increased cross-border collaborations among utility firms (Kaul, Conçeeicao, Le Goulden, and Mendoza, 2003). There is evidence that the use of collective action in the provision of services, and in the use of resources are becoming useful particularly to developing countries with less than ideal telecommunications, water, transportation and energy sectors. It is the increasing regionalization of networks through the sharing of knowledge and infrastructure that has precipitated the role of regional regulatory associations for regional infrastructure development. Improving our knowledge of utility supplier collaborations and the services they provide is essential to improving production and supply within regions that could benefit most from cross-border collaboration of this nature.

There has been a growing consensus that regional regulatory agencies provide regional club goods that were previously neglected (Estevadeordeal et al. 2004). Less is discussed the presence of networks of regional utility operators that have now become important participants in the efforts to improve utility performance regionally. While regional regulatory institutions and the services they provide have been studied, there is little research dealing with the collaborations of the utility providers themselves. A study is, therefore, needed to clarify the functions and economic impact of these networks. Although the networks of associations are sometimes viewed as cartel-like in nature, it has been argued that such networks can increase competitiveness of its members. Networks of operators provide cross-border and national services, and operating as a single entity may improve the lobbying opportunities of operators and gives them a bigger voice in influencing policy. However, the potential to improve individual supplier's efficiency is strong for cross-border associations since geographical obstacles and other factors lower the likelihood of monopoly behavior. A discussion of these privately supplied cross-border infrastructure related goods is necessary to broaden the awareness of some of the issues that are specific to these types of goods and to encourage further discussion. Given the differences between the countries, it is important to conduct multivariate analysis to control for individual characteristics that might have an impact on the utility usage in the different regions. The individual country-specific variables include Gross Domestic Product per capita and population density, both in level and lags. The outcome variables are energy (measured in kg of oil equivalent per capita), and electric (measured in kWh per capita).The primary variables of interest are courses and training. Courses refer to the various different instructions designed to develop the core competencies needed for successful production as well as managerial performance. Training refers to the various different forms of workshops in the utility sector that are available within the region. The methodology employed makes use of on-the-job, instructorled sessions with opportunities provided for field trips, demonstrations, hands-on applications and knowledge assessments where appropriate. The methodology employed in this study consists of ordinary least square regression estimating electric and energy consumption.

The rest of the paper is as follows: section 2 provides a structure of the regional supplier associations in the Caribbean and Latin America, section 3 explains the need for regional utility suppliers' collaboration, and section 4 outlines the goods and services provided by operator networks. Section 5 analyzes the case of energy and electricity for the LAC countries, and section 6 provides conclusions.

\subsection{The structure of regional supplier associations in the Caribbean and Latin America}

Traditionally, supplier's association is defined as a group of a company's suppliers that are brought together on a regular basis in order to achieve strategic and operational alignment through the development of awareness, education and implementation of the program (Hines and Rich, 1998). These are usually voluntary networks with their set of rules and regulations that are designed to enhance cooperation among suppliers (Sako, 1996). The supplier associations communicate via meetings, workshops and various different ways to develop programs that would improve supplier performance, and strengthen the relationship among the association's members.

In this study, regional utility suppliers associations are different in the sense that the service being supplied by the participating firms is often the end product itself. Companies forage international linkages as a means of procuring critical inputs that are not the standard requirements for production. The utility companies collaborate with other firms that are capable of supplying or contributing to the strategic components of the operation. As a result, the terms supplier and operator networks or associations are used synonymously. Regional utility suppliers associations are often initiated voluntarily and can consist of companies that typically serve different markets or countries. Such networks have specified strategic goals and benefits to be derived by its members (CARILEC Annual Report, 2010).

Table 1 above outlines selected utility provider associations throughout LAC countries. Regional collaborations among firms or governments in the provision of utilities are not a new phenomenon. Within country networks of firms of this nature has existed since the 1960's. Cross-border supplier collaborations took off in the early to mid1970's and continued to be established in the 1980's and 90's during the peak of infrastructure reform efforts in the region. The collaborations have been formed regionally with the geography extending from country-wide associations of utility providers to cross- country systems of network. 


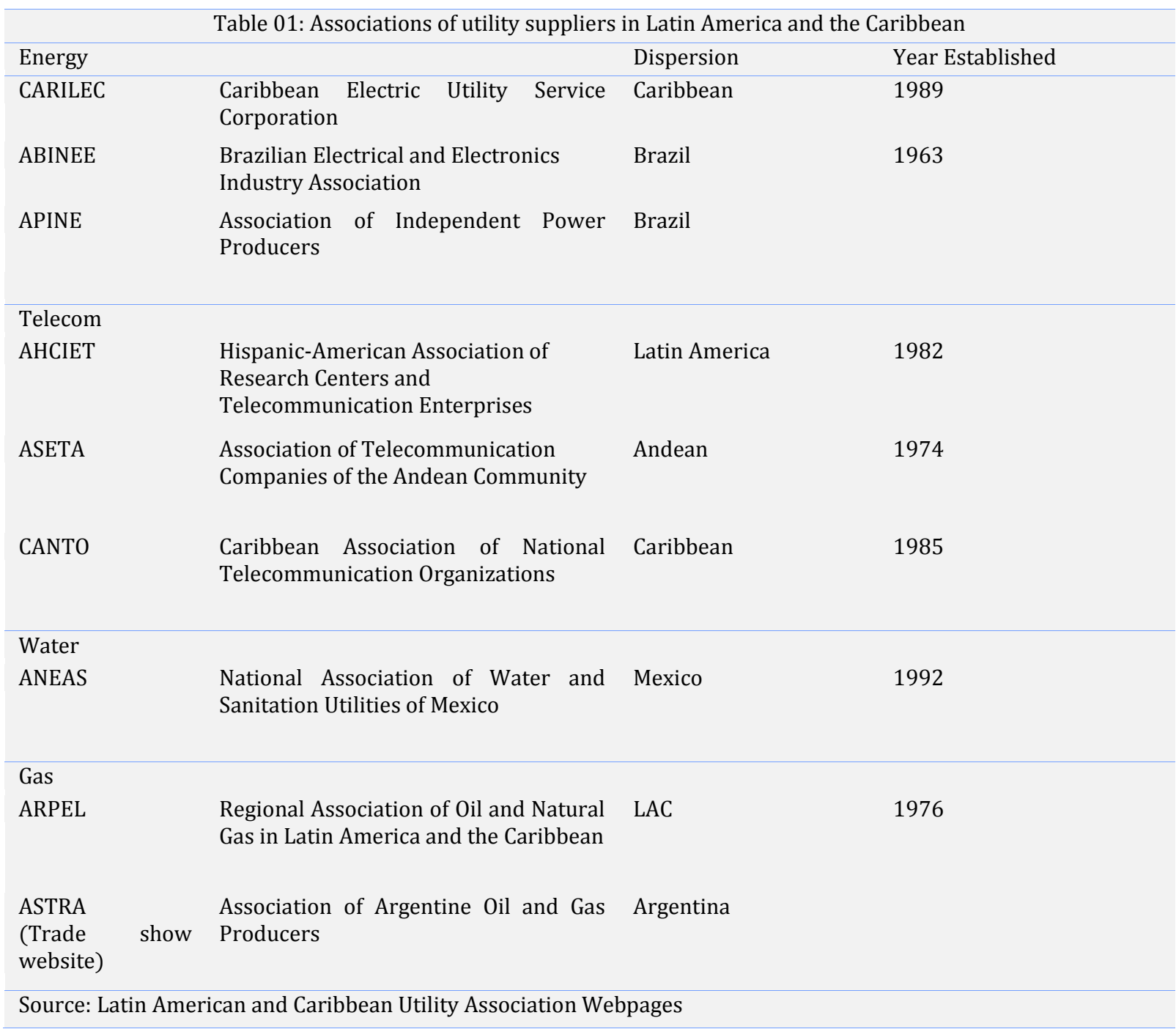

Dispersion (Table 1) and the number of association members could indicate the likelihood of cartel-like behavior. Fewer members and tight dispersion improve the likelihood of reduced competition. Since markets served are typically demarcated by country boundaries, when there are multiple members from a single country, the possibility of colluding or competing improves. Effective regulatory governance is essential in cases where political and market power may be unevenly distributed. Research on country level regulatory governance reveals that regulatory agencies are effective only to some degree. Appropriate procedures, mechanisms, and instruments must be in place to guarantee the independence of the regional regulatory agency from political authorities, where certain countries have a strong influence on regional policies due to strong political influence from a dominant country. Sirtaine et al (2004) found that decision-making autonomy of the regulatory agency positively impacts the performance of private investment in infrastructure projects in LAC. Likewise, Estache and Rossi (2008) used firm level data of 220 electric utilities in 51 developing countries and found a positive association between regulatory agencies and more efficient firms. Regulatory agencies are also associated with increased consumer welfare. A proper regional regulatory framework that is autonomous, transparent and accountable must be implemented to administer changes in the competitive environment though regional involvements, and to deal with changing approaches to utility provision. Particular regulatory implications of the creation of regional networks in the LAC area will be discussed further in the conclusion of the paper.

\subsection{The need for regional utility suppliers' collaboration}

\subsection{Transaction cost economics}

Coordination and cooperation among network members could minimize duplication of efforts and control utility cost (Hilbert and Katz, 2002). For instance, sharing market research data could facilitate services that more closely match consumer needs and that take better advantage of current technology. Network coordination can help to determine reasons for weaknesses or problems and identify improvement programs that can be implemented through collaboration, but would be too costly for an individual utility firm. ASETA facilitated the implementation of 
joint activities to resolve issues that arose in relation to the new millennium in telecommunications systems. Resolution of such issues by a single member or firm could potentially be time-consuming and costly.

One of the most-persuasive arguments for the collaboration of utility providers is the sharing or reduction of costs associated with service production (CARILEC, 2008). For instance, if the network can share resources, the need to acquire necessary training, equipment and capacity via the market is reduced. By circumventing the market, individual providers can minimize transaction costs that would be incurred through market exchange. There is a direct cost-based argument that can be made here in support of regional integration. In some cases, the transaction costs are higher than the benefits gained from economic exchange. In such cases a private (market) solution is not feasible. For example, attending training sessions or workshops sponsored by an outside facility can be permitted if the trainee pays a certain price for the service. In addition to the cost of attendance, costs are involved to find the preferred workshop, where to access the information and at what price. These transaction costs can be divided into three main categories: Search and information costs, bargaining costs and policing and enforcement costs.

Search and information costs include costs that are incurred in determining whether the required product is available on the market, the quality distribution of the product, the best value for your money, which supplier has the lowest price and so forth. For instance, regional energy could be provided by hiring an outside firm who could supply all countries that are experiencing resource shortage. This can be a time consuming and expensive project. A cost effective approach is to collaborate with the utilities in neighboring countries to provide the service themselves regionally. By doing this, no individual country is completely dependent on an outside supplier for its services, but instead, each participating country has partial ownership and an incentive to contribute fully to the functioning of the whole.

Bargaining costs are the expenses that are incurred to negotiate an acceptable agreement with the other party in the transaction. One important cost would be the cost of creating a contract that is acceptable to both parties. Acquiring a supplier may require long-term contracts that include unreasonable concessions in order to get the desired product. The costs of such arrangements are demonstrated in long-term contracts that had to be offered to multinational utility companies in the nineteen eighties and nineties when developing countries were seeking to modernize their telecommunication systems (Krause, Handfield and Tyler, 2007). Long term exclusivity contracts were signed that could not take all conditions for growth and development into consideration. As a result, the benefits gained by developing countries from granting these contracts were limited to the infrastructure growing to a limited size that did not necessarily match demand conditions.

Policing and enforcement costs would include the cost of regulating the utility or encouraging preferred behavior of association members. These are the costs of ensuring that the other parties (typically the supplier of the service) maintain the terms of the contract. These also include the associated punishment if a party violated the terms of the contract. In the case of the regulator, this may include going through the legal system which can be a significant expense (MAF Business Plan, 2013).

Regardless of the form, monitoring the association members can incur significant costs, and it might be difficult for individual utility firms to hire and fire trainers depending on market conditions. It might be more convenient and less expensive for utilities to make other arrangements that are more permanent in nature. Supplier collaboration across borders is one such arrangement. Utilities are increasingly engaged in the production of modern and sophisticated products to the market. In an era of changing technology, the information cost incurred in the process can be high. Utility firms in the Caribbean and some Latin American countries are necessarily small, due to the relatively small economies in which they operate. Small or even large utilities often do not have access to all of the resources that are required to produce in-house. The solution to this problem is to engage in explicit contracts with outside firms. A number of specialists will exist in the region among the different utilities, and it will be cost efficient and even natural for them to form independent groups that can offer mutually benefiting services. Such collaborations can generate positive externalities and economies of scale with the potential for spillovers of innovation and know-how among firms that engage in joint development efforts and through the exchange of capacity (Girvan, 2007).

\subsection{Success of other regional organizations}

Utility firms like other profit-maximizing firms are interested in increasing their competitiveness to take advantage of market opportunities and augment their individual profits. As such a primary motivation for joining a network is the perception that such collaborations could result in some form of net benefit for the firm. The abundance of regional organizations suggests that there are some benefits to be derived from cross-firm and cross-border associations, and therefore provide an incentive to each utility provider to subscribe to the association to gain from any of the potential benefits of such organizations. Collaboration, however, is a selection problem where the consideration of the whole is relevant. Nevertheless, for collaborations to function well, the networks must adopt a 
win-win strategy for all its partners. Although member companies participate for self-improvement (probably measured in terms of profits), joint benefits are necessary for the success of the whole organization (Degraeve et al. 2000). This could be challenging in the case of cross-border suppliers that may have conflicting interests, even in the presence of a common regional objective. From a game-theoretic viewpoint, the regional associations consist of players (representatives of each utility supplier), each of whom is confronted with a set of strategies that are implemented through decisions made and actions taken by the firm. The payoff to each participant is reflected in the perceived benefits from collaboration. Association members are willing to collaborate only if they expect to profit from doing so. It, therefore, appears that trust is essential for successful partnerships. Incentives that guarantee a positive benefit or at least a zero loss situation for individual network members have to be created that are binding and guarantees required behavior. Without the correct incentives, certain information and techniques may be kept secret, and the effectiveness of the association may be compromised (CARILEC, 2010).

\subsection{Learning/capacity building}

Some firms want to gain access and benefit from a more competitive supplier's knowledge. With the rapid pace of technological change in the telecommunications industry, it is often necessary for firms to form cooperative networks to keep pace with developments which require more resources, intellectual capacity and management skills than is available to a single firm (OECD, 1996). Capacity limitations can be effectively addressed by pooling human capital, and by sharing knowledge and skills, and reducing administrative costs. The possibility of capacity building through networking, however, could potentially create selection bias. More needy networks may have a stronger incentive to join, thereby minimizing the potential benefits of the association. On the other hand, the bias may be towards larger and successful utility providers who will seem more attractive to potential partners, because they can offer better technological and managerial capabilities.

\subsection{Sharing best practice}

Utility suppliers in Latin America and the Caribbean facing resource limitations may lack some of the essential tools, or may be structurally unprepared to sustain continuous improvement in service that match changing consumers, environmental and other needs. Each member of the association can benefit from information sharing, training and innovation within the group, thereby facilitating improved industry practices and techniques. Collaboration of suppliers provides a forum that allows discussions and sharing of experience. Significant cost savings are possible if firms within the regional organizations are prevented from reinventing the wheel and benefiting from economies of scale.

\subsection{Political networking}

Collaboration can provide the LAC region with a platform that would enhance their international recognition. Regional networks provide a venue for negotiations that can result in consensus building that might be difficult or impossible by individual participants in larger international settings.

\subsection{Goods and services provided by operator networks}

Regional utility organizations could be viewed as voluntary groups or clubs where utility companies from different countries within a certain region collaborate in order to create a common good. This common good satisfies the properties of club goods partially and as such are impure public goods or club goods.

\subsection{Understanding regional club goods (RCGs)}

A good is considered to be a club good if it is non-rival in its consumption but exclusionary in its benefits. Club goods are a special class of public goods. As such, a regional club good is a service or resource that is consumed across national borders, and whose benefits are, therefore, shared amongst neighboring countries. RCG's may be non-rival in consumption and are exclusionary in benefits (Ferroni, 2002).

The non-rival property implies that the consumption of the good by individuals within a single nation does not lower or does not mitigate the consumption of the same good by other individuals within a different country because one country's consumption does not lower the supply of the good. The non-rival characteristic holds only if the size of the club is limited. Because the use of a club good involves sharing, partial rivalry of benefits develops as clubs grow, and larger memberships creates congestion effects and detract from the quality of the club good (Cornes \& Sandler, 1996). When this size is reached, the cost to additional members start to outweigh the benefits that can be derived and the effectiveness of the collaboration diminishes. Congestion effects might be important where scale economies are involved in the production of the RCG. 
The exclusionary property suggests that it is possible to limit the benefits of the product to only the member organizations. The exclusion of benefits property of club goods means that the effective price can be charged for the use of the good. The combination of the non-rival and exclusionary properties of club goods means that the goods and services that are provided by regional utility collaborations can be considered as club goods that generate benefits that are private in nature. This is because non-members who do not contribute to the goods production are excluded from its consumption.

The excludability of benefits property generates some features of the club good that are not present in other club goods. Discussion of these features relies largely based on Cornes and Sandler (1996).

\section{Volunteerism:}

Privately owned and operated clubs such as utility associations must be voluntary. Members join the club because they believe that they or the organization that they represent will benefit from their participation and that these benefits outweigh any costs associated with membership. Because non-members of the club can be excluded from its benefits, a potential member may choose not to consume the good if the net benefits are not large enough. If the product was publicly provided, the choice to participate or not as indicated by the membership fee of a private club is not possible.

Exclusion mechanism member incentive:

The exclusion of benefits characteristic of club goods suggest that benefits to non-subscribers can be effectively withheld. This possibility of exclusion creates an incentive for potential members to join the club and pay fees and other dues. This mechanism works only if the cost is smaller than the benefits gained from the club as a member.

\section{Dual decision:}

To make a club good available, two decisions have to be made: first, the amount of the shared good must be determined, and second, user benefits or privileges must be distinguished from non-members. A part of this decision must also involve distinguishing privileges among members themselves in cases where member discrimination is practiced, so that not all members pay the same fees and dues. If the good was publicly provided, the only decision that must be made is in regard to the quantity of the product that must be made available.

\section{Optimality:}

Because there is a price mechanism that excludes some people from the benefits of the club good, it is possible that clubs can achieve a set of allocations that is Pareto optimal. An optimal number of collaborations can exist so that no member or set of members can improve their situation by creating a different club. Usually the only way to achieve a Pareto optimal production of a club good is to involve government provision of the good (Samuelson, 1954).

Production characteristics may also be important in defining a club good. Regional club goods may be considered to be club goods because their production requires collective action, and are thus dependent on regional cooperative efforts. ${ }^{1}$ In some cases, regional collaboration of utility suppliers emerged as a result of encouragements from national governments and other international organizations that have an interest in influencing certain developments or behaviors within a region.

\subsection{Goods and services produced by regional Utility clubs}

Events and meetings qualify as club goods because non-contributors access can be restricted, and meetings can be held simultaneously. Meetings are a source of net revenue for regional organizations. Equipment sharing is an opportunity for association members to share available resources such as gas lines, internet highways and electricity. Promotions made by regional suppliers associations usually involve the dissemination of information about the project, activity or goal of the organization that has regional implications. Promotions are often facilitated via sponsorship, public relations and trade shows. Capacity building could be viewed as a private good with standard properties of rivalry in consumption and excludability. Capacity building satisfies the basic characteristic of a club good in the sense that capacity building comes at a price to the participants but at the same time joint consumption does not significantly affect the benefits derived by each member up to the point of overcrowding. Best practice by utility firms refers to a method, activity or procedure that outlines the optimal way to achieve certain desired outcomes or solution to utility-related problems. Best practice may be determined through research and or experiences and can be reliably implemented and used by utility firms regionally within a particular sector. The most-applicable contribution is important in determining the value of the output, but the use of less compatible

1The Inter-American Development Bank (2005) defines a RPG as any good, commodity, and service, systems of rules or policy that is public in nature and that generates shared benefits for the participating countries and whose production is a result of collective action by the participating countries. The regional dimension of the definition is important, because if countries do not cooperate to produce the good, then it is not an RPG even if the benefits of the goods are shared once it is produced. 
information with particular institutional features could also contribute valuable information or guidance that helps to form the basis for action in accordance (Berg and Horrall 2008).

\subsection{The case of energy and electricity}

Economic growth in Latin America and the Caribbean has increased considerably during the past decade. This growth has been helped by widespread investments in power generation, transmission, and distribution that increased the provision of electricity and energy services to households, commerce, and industry (CARILEC, 2010). The region has focused on cost effective training solutions to the human performance needs of electric and energy utilities, with a view to optimizing their human resource capability, profitability and general acceptability among the communities that are served and advancing the development of the power and energy industries in the region. In this section, we discuss the potential impact of such training initiatives on the usage of electric power and energy in the LAC region.

Figure 1: Energy use in Latin American and Caribbean countries versus World energy use

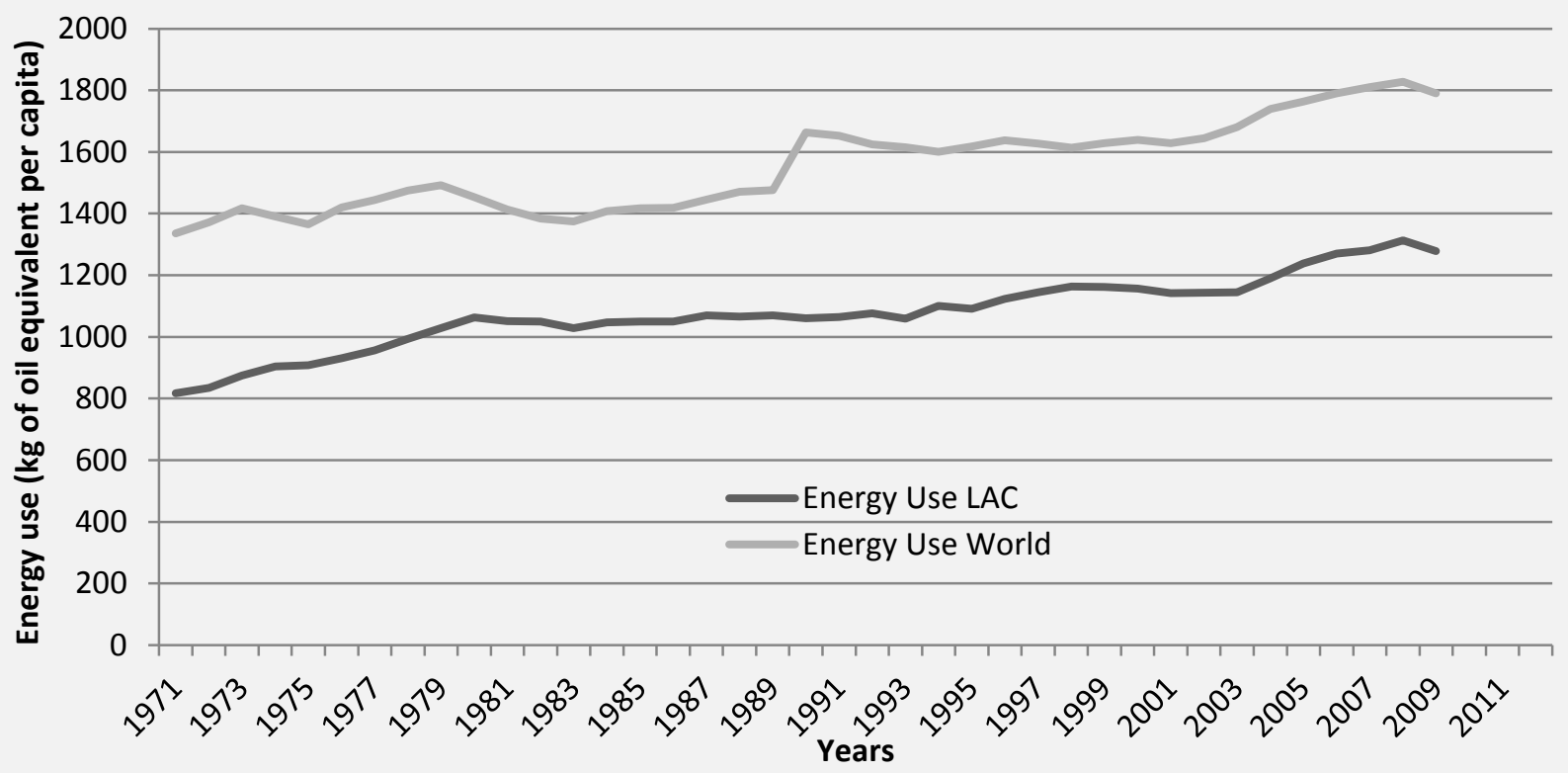

Figures 1 and two above show the usage of energy and electricity, respectively in the LAC region versus the World usage. According to the data from the World Bank, energy use refers to use of primary energy before transformation to other end-use fuels, which is equal to indigenous production plus imports and stock changes, minus exports and fuels supplied to ships and aircraft engaged in international transport.

Figure 2: Electric use in Latin American and Caribbean countries versus World electricity use

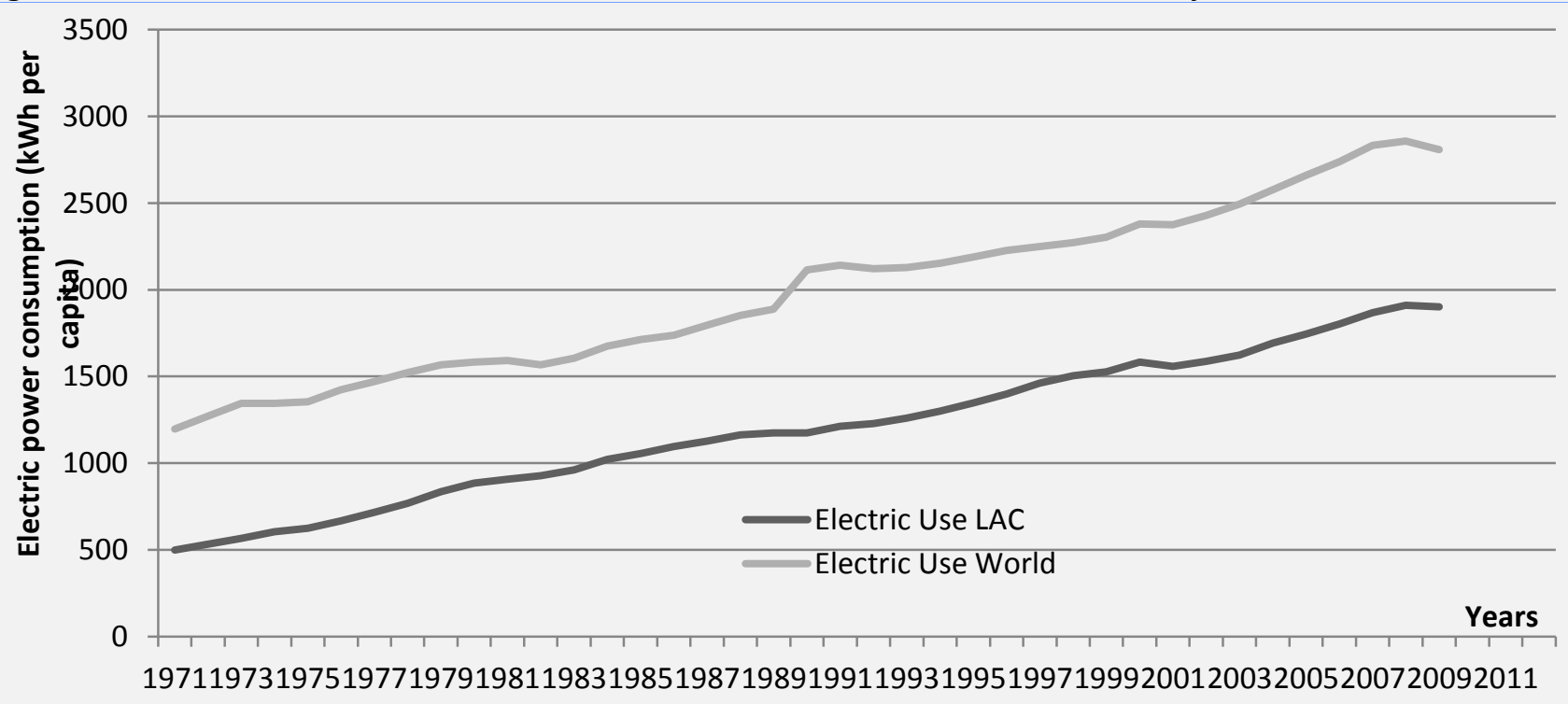


Electric power consumption measures the production of power plants and combined heat and power plants less transmission, distribution and transformation losses and own use by heat and power plants. There is a clear upward trend is the usage of both electricity and energy in the LAC region, with the former having a substantial increases over the past three decades. The primary question is whether there is increased usage of electric power and energy in the LAC region owing to association effect such as training initiatives and course offering in addition to income and population effects.

\subsection{Income and population effects}

Mishra et al. 2009, found that there existed bidirectional Granger causality between energy consumption and GDP, with each exerting a positive impact on the other, but the GDP effect on energy consumption appeared to be larger than the energy effect on GDP. There is a strong relationship between growth in economies and energy consumption. Electricity, a representative form of energy, carries the same relationship. In particular, growing energy use is an indicator of economic growth, as greater energy use generates higher productivity levels. Small countries, such as those in the Caribbean regard electric utilities as an essential infrastructure that facilitates economic growth by creating a reliable and efficient access to power supply to support production, growth and development. On the other hand, countries with higher per capita GDP also experience a corresponding increase in electricity consumption as households become more sophisticated in their choice and use of household essentials and luxuries that are afforded by higher incomes. As energy availability in the economy grows, there is an increased demand for energy to run motors, fuels for transport and other applications. As production modes change, energy becomes a vital part of powering investments, and supporting increased productivity. This is true, even though the responsiveness of energy consumption to per capita income changes may be small (Darmstadter, 2004). In the future as the Caribbean countries adapt more efficient energy usage, their strategies will shift towards saving energy and substituting fossil fuels by renewable energy sources (Gazzoni et al. 2010).

Fuel constitutes an important component of energy consumption in Caribbean islands, and as the population becomes denser, the dependence on private transportation diminishes. Data shows that cities with high urban density tend to have dependable public transportation, and are, therefore, consuming less energy compared to less densely populated areas. Low-density developments are often associated with greater travel distances, higher car dependence and vehicle distance travelled, relative to high-density areas. This means that the denser the population, the less energy is used for transportation (Newman and Kenworthy, 1999). Many countries in the Caribbean in efforts to increase worker morale and efficiency offer company-sponsored public transportation and support car pools. Many companies in Jamaica, for instance, adopted this policy, which resulted in lower transportation costs for employees, as well as fuel conservation from reduced usage of private vehicles.

On the other hand, a positive correlation between population density and energy use may occur because many Caribbean countries are limited in the forms of energy that can be produced and therefore to which consumers have access. Krey et al. (2012) argues that the share of solid fuels including coal in residential energy consumption in countries such as China is declining as the residents become more affluent. Some Caribbean countries have low per capita income and depend on traditional biomass fuels such as firewood, charcoal, and plant and animal waste. A substantial amount of their energy demand is also in petroleum, despite efforts to accelerate the transition to cleaner more sustainable energy use in countries such as Antigua and Barbuda, Nevis and St. Kitts, St. Lucia, St Vincent and the Grenadines, Bahamas, Dominica, and Grenada. Jamaica also has an initiative to increase the use of wind energy (Makhijani et al., 2013).

\subsection{Network Association effects}

Advances in energy infrastructure development could potentially imply switching from the use of traditional fuels on which the Caribbean islands are dependent, reflecting a reduction in energy and electric use from these sources. The estimated results, however show a positive correlation between the regional association's effect (measured by number of courses and the number of training programs, each lagged one period) and energy and electricity uses, although the effects on electric use are not statistically significant ${ }^{2}$.

As regional organizations like CARILEC become more active in building the knowledge base, utilities within the region benefit from increased ability to build and develop energy infrastructure. Caribbean countries are increasingly pressured to find more efficient ways of producing energy, including increasing the mix of electricity generation, transmission, and distribution. The primary goal is to meet the growing demand for energy and electricity in particular as the region's countries develop. However, finding more efficient ways to produce alternative and cleaner sources of energy is increasingly relevant and important (Makhijani et al., 2013). Since 
access to reliable sources of energy is less than perfect in the Caribbean, any increase in output due to benefits from association services, will be immediately absorbed by unsatisfied and increased energy demands.

Course offerings and training could generate positive reinforcement within the sector, but its effect on electricity usage is likely to be limited. The region recognizes the need to provide power supply at the lowest possible cost, with the highest reliability, and with limited environmental burden. This means a gradual switch to cleaner, more reliable alternative sources of energy, such as bio-diesel and solar power (CARILEC, 2008). The association's contributions while important may be too small to reflect on electric usage in the Caribbean.

\subsection{Conclusion and policy implications}

Regional associations, such as CARILEC provide important services to electric utilities in Latin America and the Caribbean, but solutions to energy issues in the region require a more comprehensive approach to capacity building and reform. The challenge for a comprehensive policy is that Caribbean islands are relatively small in size and population, and therefore have limited ability to benefit from economies of scale in administration, technical support and production. Associations such as CARILEC, can do much through regional cooperation to increase benefits from economies of scale, by sharing and creating a broader knowledge base. With the exception of Trinidad and Tobago, Caribbean countries are not major producers and exporters of energy (Yépez-García and Dana, 2012), hence, there is a need for the region to formulate and enact policies that will address the long-term requirements of the region. Any sustainable policy reform must consider demand control, the use of renewable forms of energy, improvements in energy efficiency (World Bank 2010), regional integration of energy markets, and regulatory reform. Thus we suggest the following:

First, policy makers have to create a culture of conservation among residents, which would minimize energy use and limit waste. Second, the sources of renewable energy must be sustainable financially and environmentally. Some countries have begun to examine these alternatives, chief among which include increased use of wind energy in the region (Wright, 2001). Energy efficiency must be improved by accessing all untapped sources of clean energy within the region and by exploring means of minimizing waste (Gazzoni, et al., 2010). Countries must explore opportunities to help neighboring nations to distribute better and commercialize energy resources in order to protect markets against price volatility. (World Bank, 2010).

Third, perhaps one of the most-significant reforms to address the region's energy needs would be the integration of the region's energy markets. The power sectors in the Caribbean, for example, are comprised of small fragmented and isolated power systems, and electricity demand is outpacing production rapidly. One apparent solution to keep up with demand is to create a network of pipeline connections between countries (Gerner, 2010), possibly by building submarine cable connections and sub-regional power markets. An example of regional integration initiative in Latin America include the South Gas Pipeline Network comprising Argentina, Bolivia, Brazil, Chile, Paraguay, Peru and Uruguay (World Energy Council, 2008).

Finally, any solution involving regional interconnection or cooperation is coupled with the challenge of creating the requisite regulatory framework to handle changing approaches to energy provision. A central authority to initiate the correct incentives and to encourage the appropriate environment that sustains collaboration is necessary to ensure well-functioning cross-country networks. With some creativity and appreciation of the region's needs, regulatory governance can successfully contribute to the improvement in the regions provision and use of energy.

\section{References}

Berg, S.V., and Horrall, J., 2008. Networks of regulatory agencies as regional club goods: improving infrastructure performance. Review of International Organizations, 3(2): 179-200.

Brown et al., 2006. A handbook for evaluating infrastructure regulatory systems. World Bank, Washington, D.C
CARILEC
Annual
Reports.
2006-2011.
Available:

http://www.carilec.com/index2.php?menu=annual_reports\&title=Annual\%20Reports\&id=other

CARILEC Position Paper on Energy Policy. January 2008.

CARILEC Position Paper on Regulation and Renewable Energy. March 2010.

Cornes, R., and Sandler, T., 1996. The Theory of Externalities, Club goods and Club Goods (2 ${ }^{\text {nd }}$ ed.). Cambridge University Press.

Darmstadter, J., 2004. Energy and population, Resources for the Future. Issue brief 04-01

Degraeve, Z., Labro, E., and Roodhooft, F. 2000. An evaluation of supplier selection methods from a Total Cost of Ownership perspective. European Journal of Operational Research, 125 (1): 34-59.

Estache, A., and Rossi, M.A.,2008. Regulatory Agencies: Impact on Firm Performance and Social Welfare. World Bank, Washington, DC 
Estevadeordeal, A., Frantz, B., and Nguyen, T. R. (Eds.). (2004). Regional Club goods: From Theory to Practice. Washington, D.C.: Inter-American Development Bank.

Ferroni, M., 2002. Regional Club goods: The Comparative Edge of Regional Development Banks. Conference on Financing for Development: Regional Challenges and the Regional Development Banks at the Institute for International Economics.

Gazonni et al., 2010. Sustainable energy in Latin America and the Caribbean: Potential for the Future. Science for a better life: Developing regional scientific programs in priority areas for Latin America and the Caribbean, 3 : 114.

Gerner, F., 2010. Regional Energy Solutions for Power Generation in the Caribbean: An Assessment.10th Platts Annual Caribbean Energy Conference, January 28-29, Aruba.

Girvan, N., 2007. Towards a Single Development Vision and the Role of the Single Economy. Twenty-Eighth Meeting of the Conference of Heads of Government of the Caribbean Community (CARICOM).

Hilbert, M., and Katz, J., 2002. Toward a Conceptual Framework and Public Policy agenda for the information Society in Latin America and the Caribbean (Chapter V)

Hines, P., and Rich, N.,1998. Outsourcing competitive advantage: The use of supplier associations. International Journal of Physical Distribution \& Logistics Management, 28 (7): 524 - 546.

Kaul et al., (2003). How to Improve the Provision of Global Club goods in Providing Global Club goods: Managing Globalization. K., Inge, P., Conceição, K., L., Goulven, \&R., U., Mendoza (Eds.). New York: Oxford University Press.

Krause, D., Handfield, R., and Tyler, B., 2007. The relationships between supplier development, commitment, social capital accumulation and performance improvement. Journal of Operations Management, 25 (2): 528-545.

Krey, V., et al., 2012. Urban and rural energy use and carbon dioxide emissions in Asia. Energy Economics, 34: 272283.

Makhijani, S., Ochs, A., et al., 2013. Jamaica Sustainable Energy Roadmap: Pathways to an Affordable, Reliable, LowEmission Electricity System. World watch Institute, Washington DC

Management Accountability Framework (MAF) Business Plan \& Budget. Fiscal Years 2013-2016. Office of Utilities Regulation.

Mishra et al., 2009. Credit Market Development and Economic Growth in India. Middle Eastern Finance and Economics. ISSN: 1450-2889 Issue 5.

Newman, P., and Kenworthy. J.,(1999). Sustainability and Cities: Overcoming Automobile Dependence. New York: Island Press.

OECD Proceedings. 1996. Towards Sustainable Transportation, the Vancouver Conference, Vancouver, British Columbia.

OPEC Fund for International Development (OFID) Quarterly. 2009. 1(3).

Poumanyvong, P., et al., 2012. Impacts of Urbanization on National Transport and Road Energy Use: Evidence from Low, Middle and High Income Countries. IDEC DP2 Series, 2(5).

Regional Target Group (RTG). 2012. Harmonizing Water and Energy in the Americas. $6^{\text {th }}$ World Water Forum.

Sako, M., 1996. Supplier associations in the Japanese automobile industry: collective action for technology diffusion? Cambridge Journal of Economics, 20: 651-671.

Samuelson, P., 1954. The Pure Theory of Public Expenditure. The Review of Economics and Statistics, 36(4): 387389.

Sustained, S., Pinglo, M.E., J. L., Guasch and Foster, V., 2004. How profitable are private infrastructure concessions in Latin America? Empirical evidence and regulatory implications. The World Bank.

World Bank. 2010. Energy Matters: Achieving Secure and Clean Energy in Latin America and the Caribbean. IBRD Results.

World Energy Council. 2008. Regional Energy Integration in Latin America and the Caribbean Executive Summary. Promoting the Sustainable Supply and Use of Energy for the Greatest Benefit of All.

Wright, R., 2001. Wind energy development in the Caribbean. Renewable Energy, 24 (3-4): 439-444.

Yépez-García, R. A., and Dana, J., 2012. Mitigating Vulnerability to High and Volatile Oil Prices: Power Sector Experience in Latin America and the Caribbean. World Bank, Washington, DC 